\title{
EDIPO Y SEGISMUNDO: LA LIBERTAD EN SÓFOCLES Y CALDERÓN*
}

\author{
BENJAMÍN GOMOLLón \\ IES SANT ANDReu (BARCELONa)
}

Calderón ha sido estigmatizado como ideólogo de la Contrarreforma católica en la España del Barroco. Estamos acostumbrados a imaginar, en general, las posibilidades del arte y el pensamiento del siglo XVII como estrechamentelimitadas, cuando no canceladas, por una obligada confirmación de determinados patrones ideológicos fijos e indiscutibles, de clara raigambre religiosa, en el seno de una sociedad vigilada, popperianamente cerrada bajo la atenta mirada de la Inquisición. La virtualidad del arte queda, según ese estereotipo, reducida al manierismo, al virtuosismo formal, incapaz de oxigenarse y revitalizarse con la discusión de los problemas reales y exteriores, tanto de formas como de ideas, que es la sustancia y la legitimación de su

\footnotetext{
* Este breve ensayo nació como una conferencia, destinada a la Universidad de Gerona y, meses más tarde, presentada también en las aulas de la Universidad de Zaragoza. Su origen oral, ahora solo disimulado en lo imprescindible para darla a la imprenta, me lleva a no cargarla en exceso de notas, que oscurecerían sus valores discursivos, ni de citas literales, que el lector puede suplir fácilmente recurriendo a los textos, tan conocidos.
} 
capacidad dialógica y problematizadora. Si el arte no recibe, en efecto, la transfusión de la sangre viva de la época en la que se inserta, perece en una agonía de ensimismamiento, de abarrocamiento, de culteranismo vacuo, para utilizar una imagen proveniente de la misma literatura. $\mathrm{O}$ en vanguardismos sectarios y pretenciosos, para venir más cerca de nuestro tiempo.

$\mathrm{Y}$, sin embargo, podemos con justicia preguntarnos si un artista de la talla de Calderón puede vivir como tal sin compartir las claves de humanidad, sin respirar el aire de su tiempo. Pudiéramos acaso decir, metafóricamente, que la poesía, el teatro, deben batir sus alas, no en la quimérica pureza del vacío, sino en el aire que los sostiene, viciado o no, como a la paloma kantiana. La mirada, la escenificación de los conflictos, en Calderón, incorporan una concepción radicalmente trágica de la realidad, radicalmente humana, radicalmente, por ello, sofoclea. No merece, entonces, si nuestra interpretación es correcta, reivindicaciones desde el exterior de su poética, como las, a mi entender, retóricas y ventajistas apologías en que la generación del 27 hizo estallar la preciosista pirotecnia poética de Góngora y que podrían extenderse al estilo deliberadamente gongorino de pasajes clave tanto de tragedias como de autos sacramentales. No debiéramos transformar, como alquimistas, un poeta del XVII para inventarnos un glorioso antepasado estético del arte por el arte, ante cuya imagen podemos permitirnos hombrear con pose heroica, en un culto orgiástico de contorsiones gimnásticas imitativas, en metáforas, sinécdoques e hipálages. No porque tal ejercicio sea por completo estéril. Sus frutos dio en el llamado por algunos Siglo de Plata de la literatura española. Pero esa misma designación, que ha hecho cierta fortuna, delata el fracaso relativo de tan forzadas emulaciones, si dejamos al margen logros como el mundo lorquiano, más dependiente del genio propio de su autor que de las recetas à la mode, a las que inevitablemente todo artista, sin embargo, es deudor en cierta medida.

Volvamos, pues, a Calderón. Y no olvidemos que su lenguaje está fuertemente influido por los modos de Góngora, un artista original e revolucionario a su manera. Pero tratemos de leerlo a su propia luz, en todo caso, $\sin$ interferencias proyectivas. En la trama ideológica en la que sitúa, sin duda, uno de los problemas medulares de su época, y también de todo tiempo y lugar, el problema del destino y la libertad. En este sentido, Calderón es vanguardista, moderno. Elige la grieta en la que se ha escindido la conciencia unitaria de la Cristiandad y que ha hecho derrumbarse la historia en terribles guerras fratricidas. La escena, pues, si miramos profundamente, se desarrolla sobre 
un decorado implícito de pugnas y persecuciones ideológicas, de sangrientas batallas, de esa tenebrosa realidad de pesadilla en que ha venido a despertarse el luminoso sueño del Renacimiento. ${ }^{1}$ Pero en el teatro, en la tragedia de escuela clásica, no es posible la superproducción aparatosa, la masiva presencia humana a las que el cine de hoy nos tiene acostumbrados. Si algo descubre el teatro griego y lega a la tradición dramática occidental es la capacidad de reducir, en el breve espacio de la experiencia del héroe, toda la tragicidad de un tiempo. Por ello no podemos juzgar a Segismundo, como no podemos juzgar a Edipo o a Ayante, como personajes solo individualmente verosímiles. Ni podemos someterlos a la aristotélica prueba de la plausibilidad realista de cuanto acontece en escena. En este aspecto cierta ventaja llevaban los antiguos helenos, ya que los héroes del mito son, por definición, por semiconsciente y compartido conocimiento del público de la polis, personajes simbólicos, flexibles, reformulables en cada uno de los avatares en que las narraciones tradicionales los sitúan. Son, ellos y sus vidas, espacios polivalentes desplazables, que fundamentan el recuerdo y relegitiman el presente. Permiten, además, especular, y ahormar el futuro. Porque la identidad del hombre antiguo es una identidad, en su expresión pública, artificialmente dada, cerrada. No tiene asomo de evolucionismo, personal o histórico. No se percibe en Eurípides el anacronismo psicológico flagrante de poner en boca de Helena sofismas gorgianos. ${ }^{2}$ No se pretende descubrir, como una especie de paleontólogo evemerista, el fondo de un Odiseo a la manera de Finley. ${ }^{3}$ Los griegos saben muy bien que Ulises, si existe todavía

\footnotetext{
${ }^{1}$ La mirada profunda que proponemos impugna la impostura de un arte puro, ahistórico, un arte que trasciende el tiempo en que vive y desde el que inevitablemente habla. Es verdad que la lejanía fingida concede al artista un referente espacio-temporal maleable, dúctil, libre de los reproches de la falta de rigor o de la excesos de opinión libre (parrhesía) frente a lo contemporáneo. Pero es una libertad fingida. El público a quien se dirige retrotrae, con mayor o menos acierto y fortuna, la obra al contexto coetáneo.

${ }^{2}$ Los sofistas también utilizan el mito como campo de experimentación para sus artificios retóricos, sin excluir la provocación: Gorgias, en su Elogio, reivindica la figura de Helena, denostada por la corriente dominante del mito. Y sirve en cierto modo de precedente, formal y argumentativo, a Eurípides, por más que en la tragedia no hay propiamente elogio de uno de los personajes en conflicto, sino extremada defensa encomendada personalmente a cada uno de ellos. Recordemos que en el derecho ático es el propio acusado quien pronuncia su discurso de defensa, aun cuando sea escrito por un profesional a sueldo.

${ }^{3}$ M. I. Finley, El mundo de Odiseo, México-Madrid-Buenos Aires, Fondo de Cultura Económica, 1961. Un clásico en los estudios homéricos, que pretende descubrir el trasfondo histórico del mundo de la épica griega, en el que se van sedimentando no solo los recuerdos imprecisos de época micénica, sino principalmente toda la realidad social de la Edad Oscura, en la que realmente
} 
de veras, es precisamente como personaje que puebla una serie de relatos compartidos que pueden ser - que deben ser - indefinidamente re-contados. Y el teatro es una de las posibilidades de recontar los mitos, pero en el medio de la comunidad de los ciudadanos. Es un espectáculo poliado, si se me permite la expresión. E inversamente: somos griegos en la medida en que hablamos de Ulises, en que lo confirmamos, una y otra vez, dentro de nuestros relatos, como nuestro antepasado, al que reinsertamos en lo contemporáneo a través del ritual narrativo o dramático. El helenismo, como descubre Isócrates, es una pertenencia de paideia, no de raza o conquista. Es una determinada afinación del espíritu, una determinada armonía con un pasado de escalas y modos heredado, concebido como superior y, continuamente, revisitado, reactualizado. ${ }^{4}$

Por ello, por ese simbolismo ${ }^{5}$ de varios planos, intrínseco al personaje sofocleo o calderoniano, es por lo que trataremos de leer, ahora, en dos niveles La vida es sueño en paralelo al Edipo Rey. Porque creemos que no es únicamente la historia de un príncipe lo que se lleva a la escena. Sino también la experiencia y el anhelo de la libertad como fundamento de la dignidad posible del ser humano. Segismundo es todos los hombres. Como lo es también Edipo. Sus tallas principescas, su forma de debatirse entre la realidad y la apariencia no distan demasiado entre sí, no dejan una muy diferente sensación de la capacidad de sus autores para explotar al máximo el choque de las antítesis y los cambios extremos de fortuna con que aquilatan el temple de sus héroes. Pero no adelantemos conclusiones. Tratemos de ir paso por paso.

\footnotetext{
fragua la epopeya, aun como memoria idealizada del pasado heroico. Nueva constatación, pues, de la inviabilidad de un arte al margen de la época en la que nace.

${ }^{4}$ El helenismo como ideología de supremacía cultural que legitima la conquista y conforma la identidad de los pueblos asimilados constituye un precedente obvio de Roma, que no altera substancialmente la idealización del referente griego, sino que lo duplica con la construcción de un humanismo de imitación, formal e ideológica. Podemos decir que la literatura latina es, aunque no exclusivamente, la continuación natural de la griega, solo que en otra lengua. No es exactamente aplicable este criterio a otros campos, como el derecho o la política.

${ }^{5}$ Insistimos en el concepto de símbolo en un sentido pleno y etimológico. La obra de arte es el negativo, la proyección invertida, la mitad rota y de perfecto encaje de la realidad. Leer el texto es convertirnos en su mitad complementaria, amoldarnos a su perfil de contornos irregulares e imprecisos. Ello es evidente en un contexto de contemporaneidad, de lectura coetánea, de asistencia a la representación gobernada por el autor. Pero es también el fin de la filología: construirnos como lectores (o espectadores) arqueólogos, capaces de alzar el semiderruido edificio de las palabras dichas en su tiempo propio. Un horizonte de perfección imposible, pero insoslayable.
} 


\section{PRIMER NIVEL: LA DIMENSIÓN HISTÓRICA}

Y voy a proceder de la manera que acostumbro, nada filológicamente $-\mathrm{y}$ espero que tampoco políticamente - correcta, pues del oficio de la filología, si, como quería Goethe, nos llegan regalos que por ningún otro medio pueden venir a nuestras manos, sin embargo mucho estorba, si se engalana en exceso, la vitalidad de la palabra hablada, esa que amaba el divino Platón y cuyo empuje quiero seguir ahora, quebrando las prisiones con que nos carga la letra escrita y su cortejo y acumulación de citas y aparatos críticamente alambicados.

Primero unos apuntes de historia. Me dio cuando concebía esta discusión por pensar, mientras repasaba mentalmente la conocida manía de identificar a Pericles con Edipo, tan repetida como condenada por tantos especialistas, que algo habría que decir sobre las similitudes entre el personaje de Basilio, rey de la maltrecha Polonia de Calderón, y Felipe II, por la manera como reducen a cautiverio al legítimo heredero. No sé si esto se ha dicho antes. Y me importa poco, de momento, comprobarlo. Se echa de ver enseguida que el destino cruel que se cebó en el personaje histórico, el infante don Carlos, queda artísticamente superado en la escena final de reconciliación, tan poco trágica, entre padre y Segismundo, ya convertido a la prudencia ejemplar y cristiana. Aquí asoma algo interesante. La benignidad del final de La vida es sueño se explica como redención del personaje, como superación de la soberbia del padre. En cambio el destino de Edipo encaja, mutatis mutandis, con la desaparición de Pericles de la escena ateniense, víctima de la peste. Por cierto que hemos de hacer notar de pasada un enorme contraste: por un lado, los efectos literarios de la peste de Tebas, a raíz de la cual todo el pueblo vive un frenesí religioso que sirve de telón de fondo a la acción. Por otro lado, en cambio, según nuestro concienzudo y astuto reportero Tucídides, ${ }^{6}$ las consecuencias reales, en la Atenas del 429 a.C., fueron de un absoluto cinismo social y abandono de los valores tradicionales, precisamente por la claridad con que el azote de la epidemia golpeaba tanto a los buenos como a los malos, aniquilando cualquier atisbo de justicia divina.

\footnotetext{
${ }^{6}$ V. Hunter, Thucydides, the artful reporter, Toronto, Hackert, 1973, una excelente monografía que ataca su imagen tradicional de historiador imparcial y objetivo. Tiene además el interés de que la estricta contemporaneidad de los hechos, que el ateniense considera imprescindible para llegar a resultados convincentes de objetividad, lo acerca de hecho a lo que hoy llamaríamos periodismo de investigación, más que propiamente historiografía.
} 
Este contraste es muy revelador. Realmente, Sófocles trata de devolver la dimensión escatológica del hecho real, la peste, que depende, no del capricho de los dioses, ni de su inexistencia, sino de la culpa del hombre que desconoce que su ser, su destino, su fatum está ahormado por la naturaleza divinal del cosmos. La rebelión no es posible. Y, si se produce, el castigo, la destrucción del individuo, en todas sus dimensiones, se hace inevitable. Apolo descarga el golpe sobre la ciudad. Edipo ejecuta, cegándose y exiliándose, la expiación del parricidio nefando, y cumple su propia maldición sobre sí mismo. Divinidad y ser humano componen un doble plano en paralelo que explica y materializa el deber ser frente al querer ser. Tebas es castigada en su týrannos, finalmente, pero también, antes, en todos los seres de la polis. Lo que hace Sófocles es devolver la dimensión religiosa, es decir, real, inteligible, de la peste, como hecho que forma parte del orden del cosmos. Y no es que crea inocentemente en que la peste deriva siempre de crímenes nefandos de los dirigentes. Sino que, más exactamente, lo que parece apuntar es que es en el mito tradicional donde hemos de buscar la iluminación que envuelve, sitúa y cuaja la comprensión de lo que pasa. De una forma desintelectualizada, dramatizada, nos asomamos con mucha mayor fuerza a la comprensión de la única realidad humanamente vivible, que no a través de un ciego ateísmo que en realidad desrealiza, deshumaniza la historia, lo que nos pasa, pues nos deja en una oscuridad total, en un absoluto desarme y desamparo frente a lo real. No es que Sófocles pretenda una restauración, o mejor dicho, una instauración sin paliativos del mito como forma mentis válida y única. Es que el arte del teatro le permite iluminar y metabolizar la sequedad terrible de la destrucción colectiva entre peste y guerra, ofrecer una visión emocional y helena, humana, de los peligros que se abaten sobre la polis. Esa es la dimensión colectiva y religiosa del teatro griego, que lo aleja de una pura y panfletaria caracterización como obras de tesis. El poeta no divide, no se significa como opinión particular, sino que utiliza los resortes de la identidad compartida para alumbrar y construir un significado colectivo. ${ }^{7}$ El hecho teatral, no lo olvidemos, termina cuando el voto del pueblo determina al tragediógrafo que ha sabido situar el conflicto en

\footnotetext{
${ }^{7}$ Otro tanto podría decirse de la comedia. Las obras de Aristófanes, tildadas a veces de pacifistas o feministas, en flagrante anacronismo, no lo son en absoluto, sino precisamente inversión festiva de la realidad para construir el ensueño de un equilibrio de paz y armonía que son imposibles. No protesta el comediógrafo contra la guerra, sino que precisamente muestra el absurdo, la ucronía de la paz campesina, mujeril o privada, cuando en realidad Atenas es comercio, hombres y estado.
} 
la conciencia del demos, a través del miedo y de la compasión, que engendran, tanto en el personaje como en el público, el conocimiento. Pathos y mathos.

De forma complementaria, sabemos que Herodoto trata de recoger todos los acontecimentos que pacientemente acumula y distribuye en su enorme fresco narrativo dentro de una determinada visión del mundo, de una cierta teología de la historia. $Y$ estamos acostumbrados a considerar que Tucídides ${ }^{8}$ procede more descriptivo, casi diríamos geometrico -o tal pretende hacernos creer-, con aséptica y programática ausencia de todo elemento mítico. Sin embargo, el tempo narrativo de la expedición de Sicilia, esa preciosa monografía inserta en su Guerra del Peloponeso, siempre se ha dicho que rezuma un aire trágico, una escritura literaturizada y grandemente influida por el pathos propio de la tragedia ática. Así que, como vemos, el camino de la proyección entre historia y tragedia es siempre de doble dirección, en un extraño pugilato entre realidad y ficción, entre reconstrucción fidedigna y construcción de significados. No en vano cuando Aristóteles levante acta de la más perfecta tragedia, la que nos ocupa, le sirve de exemplum para su distinción entre veracidad y verosimilitud, como categorías rectoras de ambos géneros, entre lo particular y lo general, con lo que consigue dar la vuelta al esquema peyorativo de su maestro Platón en contra de los poetas. Así, la literatura no es ya lo real tal cual pasó, lo que Alcibíades hizo o dijo, sino la quintaesencia de lo humano, lo que podría haber pasado porque casa con la forma de las cosas. No lejos del concepto de anthropinon, de naturaleza humana, de Tucídides, pues. ${ }^{9}$ La literatura (poesía, diría el Estagirita) está más cerca de la idea, de la razón,

\footnotetext{
${ }^{8}$ Entre los dos grandes historiadores podemos entender que ha nacido de manera madura la historia de sello personal. Si Herodoto todavía aspira a dar una interpretación helénica y religiosa de los hechos históricos, una visión que ofrece como asumible por todo su público, (vid. Th. Harrison, Divinity and History: The religion of Herodotus, Oxford, Clarendon Press, 2000) Tucídides selecciona en cambio un destinatario elitista, ofrece una personal lectura de los hechos que él personalmente recoge, criba, ordena e interpreta(vid. J. Alsina, Tucídides. Historia, ética y política, Madrid, Rialp, 1981). Controla todo el proceso de la compilación de su guerra, y se separa en ese sentido de la forma de Herodoto, o sus pendants en la dramaturgia, Esquilo o Sófocles, esencialmente integradora y poliada. Eurípides está, de nuevo, más cerca de la modernidad, de Tucídides, que los otros grandes trágicos.

${ }^{9}$ Tucídides afirma que se volverán a producir hechos semejantes a los que él investiga y narra, dada la permanencia de la esencia humana a través del tiempo. Y que él ha pretendido dotar de materiales para la comprensión del pasado inmediato y el futuro, por lejano que sea: así su obra es una adquisición para siempre, y no un mero recordatorio de circunstancias más o menos desprovistas de valor general. Se anticipa, pues, a la valoración abstractiva y genérica que Aristóteles otorga a la literatura, sin concedérsela en cambio a la historia.
} 
porque se impone al intelecto y es creada por él, que la historia o, diríamos modernamente, el periodismo, técnicas que son de recopilación de materiales. Pueden resultarnos menos creíbles, paradójicamente, en el sentido de menos comprensibles, menos dotados de legibilidad. Encaja, en cambio, la poesía en el entendimiento, porque es forma y no materia, concepto y no suceso en bruto, y además purifica de las pasiones que sin esa catarsis se convertirían en esclavizantes, de la compasión y el miedo.

Hasta aquí hemos tratado de dar su justa dimensión a la tragedia y sus relaciones con la historia, devolviendo al arte de Sófocles su cualidad de hecho religioso, de integración entre mito y polis como ámbitos de mutua relegitimación e iluminación. Cuando ya en el siglo IV a.C. el mito pierde esa virtualidad modélica y colectiva, cuando la polis se dispersa en un mundo cosmopolita y variado en estirpes, lenguas y creencias, la tragedia se convertirá ya inexorablemente en literatura, en background cultural que se adquiere en soporte escrito, pero que pierde su consanguinidad con lo inmediato y contemporáneo. Ya no será una celebración colectiva, sino que los textos se transmutarán en objetos exentos, en obras de arte, necesitadas de comentarios y didascalias. Un arte para ver y reverenciar convencionalmente, como símbolo de pertenencia a una comunidad de lectores cultos, no una performance vitalista que instruye al demos y que el demos eleva al triunfo momentáneo y único de cada festival dramático.

Historia y tragedia son, pues, discursos complementarios en la Atenas clásica, particularmente en Sófocles, para iluminar los hechos y situarlos en una red de claves interpretativas. Pero veamos, ahora, en esos mismos términos históricos, el juego de Calderón. Sigamos por el hipotético camino de aceptar que no crea una obra ucrónica, sin conexión metafórica con los hechos de España, sino que, a la manera de Shakespeare, elige una situación cómodamente alejada en el espacio, Polonia, para liberarse de la servidumbre puntillosa del historiador. Si es verdad que Basilio corresponde a Felipe II y Segismundo a don Carlos, como sugeríamos, aunque nunca reduciendo esta correspondencia a una estéril y crucigramática exégesis en clave, sin sentido literario, si eso es al menos verosímil, entonces observemos las correspondencias y las diferencias. En la realidad, don Carlos acaba envenenado en la cárcel, víctima de su propio padre, si hemos de creer en la llamada leyenda negra. En la obra, Segismundo supera el conflicto, se hace avisado, descreyendo de la realidad de lo vivido, asume el engaño - tema barroco preferido - de una 
manera no muy desemejante a la duda cartesiana. ${ }^{10}$ Gracias a ese desapego, a esa duda, en su última etapa de actividad corrige su natural, fiero y desabrido, para alcanzar el ideal de prudencia y reconciliarse con su padre. De paso recupera la legitimidad del trono que había perdido por su soberbia. Es un príncipe, un ser humano, construido a lo largo de la pieza: hay un final ascendente. En cambio, Edipo experimenta todo lo contrario. Recuperando su linaje, su legitimidad de sangre, pierde el trono precisamente por la soberbia del parricidio, aun inconsciente, cometido fuera de la porción de tiempo recreada en la obra dramática. Solo una vez vemos a Layo, y es a través del recuerdo de su muerte que el propio Edipo evoca, aún no totalmente seguro, ante una horrorizada Yocasta.

Resumamos. Calderón parece claro que trabaja sobre la relación edípica, diríamos freudianamente, sobre un tema tradicional. Parece que pudo leer versiones latinas y romances de la obra de Sófocles. Pero no es necesario que así fuera. No opera sobre la escena de Sófocles, no hay un remake jansenista de Eurípides, como sí podemos observar en Racine, que replica y reconstruye escenas enteras. ${ }^{11}$ Porque lo que Calderón desarrolla es un doble plano que Sófocles solo apunta tímidamente. Basilio es personaje y en cierto modo el autor interno de la tragedia. Es un padre que soberbiamente decide encerrar a su hijo al saber por sus ciencias predictivas el destino de inhumanidad y fiereza que le aguarda. Esa es su soberbia, su hybris. Los enfrentamientos entre padre e hijo, aun no alcanzando la eficacia en stacatto de las esticomitias sofocleas, son sumamente reveladores de esa culpa paterna que exculpa o diluye la responsabilidad de Segismundo por sus tropelías. Hay también

\footnotetext{
${ }^{10}$ De hecho es tan insistente la comparación que Descartes establece entre sueño y engaño de los sentidos que más de una vez nos hemos sentido tentados de pensar que es la obra de Calderón una de las experiencias clave para que el filósofo diseñe y desarrolle tal comparación, por más que no se trate, evidentemente, de una fuente stricto sensu.

${ }^{11}$ Pensamos ahora en la Fedra de Racine, que recoge escenas enteras del Hipólito de Eurípides, si bien son perceptibles las diferencias ideológicas, significativamente en la valoración del suicidio de la protagonista, tan condenable desde la perspectiva cristiana. La consideración de la vida humana como algo sujeto al capricho del destino y los dioses, pero dependiente en último término de la voluntad libre, que puede suprimirla, contrasta con la forma cristiana de pensar, en la cual el individuo se inserta en un mundo dotado de sentido, gobernado por la providencia y con la vocación de la salvación como horizonte, quedando la vida en las manos de Dios. La originalidad católica es enfatizar el libre albedrío, por contraste con las tesis luteranas y calvinistas que subrayan la fe y la predestinación, con olvido de las obras y la libertad, como valores cardinales para comprender el drama de la salvación. Racine, como los jansenistas, muestra una cierta proximidad doctrinal a la perspectiva protestante.
} 
otra diferencia terrible. La muerte de la madre del príncipe al nacer éste es ya presentada como la primera muestra de la crueldad innata de Segismundo. Segismundo es maldad desde la más pura de las inocencias, contiene la culpa cifrada en su destino aun antes de nacer y su nacimiento es ya un asesinato de quien le da la vida. ¿Evita el tema del incesto por ser demasiado horrible en una pieza de la Contrarreforma? ¿Por qué desdibuja, si no, la utilidad del personaje femenino de la madre? Quizá por verosimilitud: una madre no habría tolerado el encierro apriorístico de Segismundo. Quizá. En todo caso, eso le permite concentrar la dramaticidad en la relación entre padre e hijo. Un padre que encierra y libera a Segismundo a capricho. Que lo engaña y le hace creer que su reposición en la dignidad principesca ha sido solo un sueño. Layo no tiene ninguna de tales prerrogativas dramáticas. Es una sombra, una Erinia que se venga desde la oscuridad de su asesino e hijo. Y Calderón quiere superar el conflicto. Cree en su personaje. No se hace sabio tras la caída definitiva, como sucede en las tragedias griegas. Sino antes: rehabilita su condición y se transmuta en un ejemplo de príncipe cristiano dueño de sus actos. La escena final es una especie de anagnórisis entre su naturaleza de príncipe y su comportamiento moral. Se reconstruye el orden natural a través de la libertad, del libre albedrío de Segismundo, que obra en función de la salvación. Y no se me diga que ese final desnaturaliza la tragicidad de la obra, pues ¿qué diríamos entonces de la Orestíada de Esquilo? ¿O del Alcestis de Eurípides? El final desgraciado no es elemento obligado de la tragedia, a la que más bien define el conflicto inconciliable y la extremosidad, la hybris del héroe. Que son las pasiones que Segismundo supera para hallar la templanza, la prudencia y la justicia. Y que hacen de Polonia, no el brumoso reino de los confines del mundo, sino un estado cristiano y ejemplar, una polis en equilibrio con la divinidad. Un espejo de la España de los Austrias, si preferimos verlo así.

\section{SEGUNDO NIVEL: EL INDIVIDUO}

Como decíamos al comienzo, Edipo, Segismundo, no son solo príncipes que se debaten por la legitimidad de su poder, por la realidad de su ser frente al sueño perturbador. Si conmueven a todos los espectadores es porque apelan a determinados mecanismos de identificación universales. Su diálogo con el público no es predominantemente vertical en este plano, de rey a vasallo, sino sobre todo horizontal, de hombre a hombre. 
Entiéndase bien. El contraste trágico exige la mayor de las polaridades entre la libertad y la esclavitud humanas, la servidumbre, no frente a un dueño igual y potencialmente vencible, sino frente al único tirano cuya fortaleza es insuperable para el ser humano: el destino. He aquí el motivo: la tragedia, hecha de contrastes irreconciliables, no puede nutrirse de medias tintas. En ella el héore se enfrenta a las limitaciones básicas de lo humano, pretendiendo afirmar su individualidad. En una cosmovisión de corte griego, este desafío está condenado al fracaso. El hombre alcanzará la resignación, la conformidad con su destino mortal, aun demasiado tarde. En un universo referencial cristiano, la posibilidad de la trascendencia altera drásticamente el conflicto, lo sitúa, no en una desmesura de individuo frente al cosmos, de mortal frente a dioses inmortales, sino en una dialéctica de vida terrena, engañosa y simplemente una prueba, un ensayo, algo teatral en su insustancialidad, frente a la vida eterna, la vida verdadera, perdurable, la gloria, que es el trasmundo de la fama auténtica, tan helénicamente concebida en sus inicios. Recordaríamos ahora el ejemplar estudio de Lida de Malkiel, la filóloga argentina y gran lectora de Sófocles, La idea de la fama en la Edad Media Castellana, ${ }^{12}$ si no tuviéramos la prevención, el miedo a engolfarnos en distingos y vericuetos de filología profesional, que ahora nos son programáticamente ajenos.

Segismundo, pues, no es un hombre sin más. No es solo un príncipe. Es un aparente bruto que ha sido instruido, sin embargo, en la luz de la fe por su mentor, nombrado por Basilio. Esto deja en su interior la chispa, la claridad suficiente para reivindicarse desde el principio como una criatura libre, capaz de decidir por sí misma, no sumergida en el océano mudo e irracional de la bestialidady la animalidad. ${ }^{13}$ Cuandocomprendequecomportarsebrutalmente es un acto de esclavitud frente a la naturaleza, que lo humano se realiza solo como rebeldía frente al deseo instintivo y primario, feroz en su educación asilvestrada, es cuando es capaz de traducir en elecciones, en problema y debate interior - los apartes le dan forma estética y dramática - cada conducta, cada actitud. Es capaz de corregirse, de elegir la virtud en aras de la eternidad de su naturaleza. Segismundo modela la tragedia en la que está inscrito por

\footnotetext{
${ }^{12}$ Madrid, Fondo de Cultura Económica, 1983.

${ }^{13}$ Es absolutamente evidente la relación de la cueva de Segismundo con la caverna de Platón. Y el deslumbramiento de la primera salida, que desata el primitivismo feroz, prepara por contraste la prudente segunda liberación, en la que el personaje alcanzará ya la superación y la salvación de su reino y su alma. No podemos ahora desarrollar esta relación, tan sugestiva y prometedora.
} 
culpa de la desconfianza paterna en la libertad del individuo. Domestica su yo y domestica su destino granjeándose la gloria, la fama auténtica, en el doble plano de soberano legítimo y meritorio, humanamente, y de individuo salvo, que ha superado la prueba de la tentación, de la vanagloria del poder terrenal. En este sentido trasciende el plano histórico de su individualidad anecdótica, para elevarse a la categoría de exemplum vivo de la autorredención prudente, de la capacidad paradigmática del ser trascendente. No es un Cristo perfecto. Pero sí un Agustín pecador que alcanza la santidad en su condición de realeza. Por ello supera el nivel histórico y se sitúa en la esfera ejemplar, simbólica de su humanidad. No mentar la redención, la superación cristiana, habría sido traicionar el esquema antropológico básico al que Calderón sirve. No podemos pedirle al dramaturgo hispano que descrea, estéticamente, de su religión, de sus creencias tridentinas. Como absurdo sería tratar de bucear en la conciencia de Sófocles, para elucidar un espurio misterio sobre el grado de creencia en los dioses del ateniense. Siempre me ha parecido de una ejemplar estupidez el título de aquel libro que rezaba: ¿creían los griegos en sus dioses? No, si le parece a usted, creían en los dioses de los maoríes. Una cosa es que no se sintieran personalmente vinculados como conciencia individual a una determinada afirmación escatológica, fideísta o racionalizada, como tiene sentido preguntarse en Europa solo después de la Ilustración, de Voltaire, y otra muy distinta es pretender rescatarlos como referencia partiendo del bastardo supuesto de una especie de increencia clandestina que nos permita hacer lecturas agnósticas de la tragedia ática. Esta obsesión, que torturaba especialmente al bueno de Nietzsche, referida a su denostado Eurípides, es un ejercicio esencialmente anacrónico, pacato y particularmente ursulino y beato. Claro que Sófocles creía en los dioses, en el sentido de que solo esos elementos de conciencia colectiva contrapesaban el doloroso sentimiento de la irrepresentabilidad, de la ilegibilidad de lo real y lo absurdo de lo humano. Los dioses son una representación, una dramatización de lo humano. Son el teatro real de lo humano. El escenario posible para el dolor, para el ser del hombre enfrentado a la muerte y a la libertad, a la elección intrínsecamente perversa. Por eso Edipo es también una imagen de lo humano, en la medida en que es un personaje que desafía al entramado del destino y la divinidad, que huye de sus padres, de sus límites estrechamente marcados por un cruel oráculo. Claro que va a encontrarse con él, con su propia destrucción. Pero en el hecho de intentarlo, de salir de sí, de renunciar a su aparente principalía 
en Corinto reside la ejemplaridad de su humana elección. No importa que la muerte diferida le aguarde, como a Clarín en el final de La vida es sueño, en el recodo de la encrucijada. Edipo es libre. Aunque al final deba pagar tributo a la humillación de su limitada humanidad, de su absoluta desgracia, de su fortuna efímera. Edipo es la libertad, de la misma manera que lo es Segismundo. Uno se salva porque se representa a sí mismo en el teatro del mundo con la mirada finalmente puesta en la gloria de la resurrección. Otro se condena, ${ }^{14}$ porque para los antiguos todos nacemos condenados y solo podemos dejar el recuerdo, nuestro breve epitafio, como legado a los venideros. Como esa tumba heroica y protectora de Colono que defendía Atenas de las invasiones enemigas. Y realmente, el anciano Sófocles no tuvo que ver la miseria de la derrota final de su patria, el 404 a.C. Su cortejo fúnebre, quiere la tradición, se vio beneficiado de una tregua ante la amenazadora pero respetuosa mirada del ya casi triunfante enemigo espartano.

Se funden, pues, autor y personaje, en esa segunda parte crepuscular que es el Edipo en Colono. Y recordemos que es en esta tragedia donde Edipo se enfrenta a la condición de padre de personajes marcados por un aciago destino. Del mismo modo que Virgilio recogió la Ilíada y la Odisea, invertidas, en su Eneida, Calderón parece desdoblar el Edipo Rey y el Edipo padre y maldecidor de Colono, en los personajes de Basilio, obsesionado por la adivinación del futuro terrenal, y de Segismundo, necesitado de le reconstrucción de su yo humano.

\section{A MOdo de Conclusión}

Quedan sin duda más perspectivas que estudiar, que aclarar en esta lectura plutarquea y en paralelo de las obras de Sófocles y Calderón. Pero ya hemos encontrado indicios ciertos de la importancia de la libertad como concepto medular en ambas obras maestras. Aun desde perspectivas tan diferentes, marcadas por la religiosidad griega, sin un trasmundo salvífico, y el catolicismo tridentino, aferrado al libre albedrío como origen de la redención. Es precisamente esta obsesión ideológica la que permite una tan brillante resurrección de la tragedia en manos de Calderón.

Y hemos trazado, también, los caminos paralelos de la historia y el teatro en ambas épocas, lo que ha ayudado no poco a entender el complejo entramado

\footnotetext{
${ }^{14}$ Entiéndase esta palabra irónicamente atribuida al contexto pagano.
} 
de relaciones que en todo tiempo y lugar se tejen entre ficción y memoria, entre personaje e individuo. $\mathrm{Y}$ nos ha permitido, también, arrojar cierta luz sobre el valor del arte teatral como fuente de reflexión contemporánea, por un lado, y como elemento de comprensión del pasado desde nuestra época, por otro. Aspectos que son clave para una más correcta valoración de las fuentes clásicas y su operatividad en los textos de otros periodos históricos.

Bastará en todo caso con que el lector encuentre alguna sugerencia fértil en estas páginas, para volver después con renovado interés a la lectura y a la reflexión de ambos autores, por igual merecedores, en lo formal y en lo profundo de su humanidad, de la categoría de clásicos universales. 